\title{
THE CHALLENGE OF SUPPORTING CREATIVE INDUSTRIES-SCOTTISH EXAMPLE
}

\author{
Joanna Markiewicz ${ }^{1}$
}

\begin{abstract}
This article aims to explore the idea of the supporting system for creative industries, which plays a pivotal role in today's economy. Creative businesses, which range from individual musicians to companies dealing with publications, demand special attention and tailor-made support services. Therefore, in this article, the analysis is carried out based on the information gained in an in-depth interview and the supporting system for creative industries, which have been functioning in Scotland and the main barriers in providing support services.

As shown by the research, a problem exists regarding a proper classification of creative industries, which causes difficulties in measuring them. Moreover, lumping creative businesses with artists to the same group results in criticism from artist communities as they feel that art is no longer being supported, only invested. This piece of research is a part of a research project, which aims at comparing the systems for supporting creative industries in Szczecin and in Glasgow. The empirical approach will be enriched by the theoretical discourse on policies shaping the environment of creative industries. This article, therefore, provides important knowledge concerning building effective system for supporting creative industries, both for scholars and practitioners (managers of business support organizations and policy makers). This knowledge and experience are especially needed in central and east European countries, where the awareness about creative industries is very low.
\end{abstract}

JEL Classification Numbers: L53, L80, R58, DOI: http://dx.doi.org/10.12955/cbup.v3.581

Keywords: creative industries, support, system, policy, Scotland

\section{Introduction}

This research work is aimed at exploring the issue of supporting creative industries, which have emerged as a creative evolution. The changes in today's economy imply an increasing role of weightless assets, creativity, and culture, which shape the demand and the supply of the market. Sectors indicated by the Department for Culture, Media and Sport's classification (DCMS, 1998) encompassing: advertising, architecture, arts and antiques, crafts, design, designer fashion, film, interactive leisure software, music, performing arts, publishing, software \& computer services, and TV \& radio are estimated to be responsible for over 4,4\% of the EU's gross domestic product and 3,8\% European jobs in 2011 (TERA Consultants, 2014).

The above figures confirm that the contribution of creative industries (CI) to the economy is indisputable, and thus the necessity of supporting creative industries should be the priority of state and regional economic policies. Even though the Creative Europe Programme (European Commission, 2015) sees the need for supporting creative industries (especially in the scope of intellectual property rights, mobility, and tax regimes), the data concerning creative industries is underestimated, which affects the delivery of support services. The problem is compounded by the fact that a great majority of creative businesses represent microenterprises.

The pivotal role of CI on national economies was initially recognized by Australia and the United Kingdom. The classification and initiatives undertaken by British DCMS has become a popular approach used by academics and policy makers in other European countries. Moreover, the United Kingdom is perceived to be the world leader in creative industries. Previous statistics (DCMS, 2015) are overwhelming evidence, which show that the Gross Value Added (GVA) for 2012-13 increased by $10 \%$, which is more than three times that of the UK economy as a whole. The United Kingdom has been undertaking initiatives directed to creative industries for over 15 years, and now one can see the effects. It is worth to take a closer look at the system of supporting creative sector basing on the example of Scotland (a country which is a part of the UK), where the author had an opportunity to conduct research on business support organizations belonging to the CI landscape in Scotland. This

\footnotetext{
1 Joanna Markiewicz, PhD, Faculty of Management and Economics of Services, University of Szczecin, brazuk.joanna@gmail.com
} 
provides valuable insights on the pillars of the system, engaged bodies, best practices and challenges, especially for the Central and East European countries, where the awareness about creative industries is low (Markiewicz, 2014).

\section{Literature review}

\section{Creative industries}

First remarks on creative sectors were made in 1947 by Adorno \& Horkheimer (1979), who criticized the American culture industry. The term culture industries was popularized by Miege \& Garnham (1979), who proposed the tree models of production depending on the character of cultural labor. They distinguished non-capitalist production (e.g. the work of the artist), capitalist cultural production (recording or receiving equipment, records or books), and integration of non-material production into value (e.g. musician performance as a part of commercial promotion campaign). Howkins (2001) proposed 15 sectors (advertising, architecture, art, crafts, design, fashion, film, music, performing arts, publishing, R\&D, software, toys and games, TV and radio, and video games), which build creative economy. The attempt to analyze creative economy through the lens of occupations was made by Florida (2002), who identified the super-creative core, which comprises the group of people directly involved in creative process (e.g. science, engineering, design, and art) and creative professionals comprising the knowledge-based workers who participate in creative problem solving (e.g. healthcare, business, and finance).

As mentioned above, DCMS classification has gained popularity not only in the UK, but also in other European countries. The pillar of defining CI through the lenses of 13 sectors was based on the assumption that those industries "have their origin in individual creativity, skill, and talent, which has a potential for wealth and job creation through the generation and exploitation of intellectual property" (DCMS, 1998). Another interesting approach was proposed in a study prepared for the European Commission (KEA, 2006). The definition encompasses circles of creative activity, in which the central place is reserved for Core Arts Field (e.g. performing, heritage). The first circle surrounding the core comprises cultural industries (e.g. music, TV, and radio). The second circle represents creative industries and activities, like design, architecture, and advertising. The external circle is connected with these industries, which depend on the previous circles (e.g. PC manufactures, mobile industry, etc.).

\section{Supporting SMEs in creative sectors}

The question, which should be posed first, is whether a state should provide any help for companies. Taking into account the fact that the majority of creative businesses are micro and small firms, the idea of supporting the SME sector should be analyzed. The roots of the concept of support programs emerged from the neoclassical theory. Despite demand and supply, which regulate the market, Penrose (1995) argued that SMEs cannot compete with large companies at the same level due to the limited access to resources. The strand of business environment plays a pivotal role in the topic of business support systems. Macroenvironment together with macroeconomic policy create a landscape for companies which influences enterprises at different stage of their development (Putnam, Leonardi, \& Nanetti, 2001). The regional and local level of business milieu are crucial for the companies' survival as well. According to Cooke \& Morgan (1998), institutions operating in the region, both formal (organizations) and informal (e.g. networks), can shape supply-side characteristics. Regional policies are also responsible for attraction and embeddedness of exogenous resources perceived as bearers of new technology, innovations, and stimuli to local suppliers (Pike, Rodriguez-Pose, \& Tomaney, 2006). Mole (2004) proposed the model for supporting small business in which an advisor offers services in 
two dimensions: how to effectively use internal management system and how to properly react to the changing external conditions.

Policy dedicated to small business should provide the system increasing the business competences and help them in access to resources. Therefore, they often assume the creation of national or regional systems aimed at supporting SME, using the activity of government-established agencies or the third sector organizations and also, in some cases, private companies.

European Union recognizes the need for supporting CI; nevertheless, no comprehensive policy on creative industries has been proposed. Recently, in 2013, the European Commission established the Creative Europe Programme 2014 to 2020, which aims to support CI in facing the digital age and globalization, reaching their economic potential, and accessing to international markets (Regulation No. 1295/2013, 2013).

\section{Research methodology}

This article presents the findings of the exploratory research on the landscape of creative industries in Glasgow as a part of a research project called "Business models of business support organizations in the European Union in the context of the creative industries-comparative research of the business support organizations in Szczecin and in Glasgow ${ }^{2}$."

The exploratory research was carried out in two phases:

1. Desk research to explore economic bases of the functioning of creative industries and business support organizations functioning in their environment in Scotland.

2. In-depth interview conducted with the organization, which collaborates with Scottish Government in the field of creative industries, in order to achieve practical information about the specifics of the system of business support organizations offering services for CI in Scotland.

While describing creative industries, both from the business and business support organizations perspective, the classification proposed by DCMS (1998) was utilized.

\section{Results and discussion}

The data analysis conducted in the phase of the desk research showed that Scotland accounts for $6 \%$ of the employment in the creative economy in the UK in 2013-2014, while London and the South East are responsible for 43\% (Bakhshi, Davies, Freeman, \& Higgs, 2015). Two biggest metropolis areas: Glasgow and Edinburgh are the economic centers of Scotland and, at the same time, the main concentrations of creative industries.

The latest statistics (DC Research Ltd. \& Cogentsi, Pirnie Ltd., 2012) indicated that CI accounted for $1.5 \%$ of Scottish Gross Value Added (GVA). CI employment was at $1.7 \%$ of the total Scottish jobs. In 2010, the largest contribution to Scotland's CI GVA was made by the following sectors: publishing, advertising, music, and visual and performing arts. Architecture and publishing were above average compared to the entire UK economy. In terms of employment, architecture, music, and visual and performing arts were the leading sectors. In comparison to the UK, the same sectors had higher average employment.

The political roots of supporting CI in Scotland lie in the Scottish political system, which is closely related to the UK macro-policy (Scotland remains a sub-system of the UK). The process of devolving

\footnotetext{
${ }^{2}$ Project carried out in the frame of Dekaban-Liddle Junior Fellowships at the University of Glasgow in 2014 2015 founded by Dekaban-Liddle Foundation, Glasgow Committee. The second part of the project is now being conducted in Szczecin.
} 
matters to the Scottish Parliament has given sovereignty, especially in the field of law, education, and local government system. As far as CIs are concerned, Scotland has been following the policy outlined by the British Parliament since 1998. The last important legal acts concerning these sectors were the bill establishing Creative Scotland (Scottish Parliament, 2008) and the strategy for creative industries (Scottish Government, 2011). Both documents assume an important role of Creative Scotland as the main "quangos" (quasi-autonomous non-governmental organizations-founded by government and operating at arm's length from ministerial control). Thus, the main goals, like achieving joint approach to sector's growth, increasing scale and commercialization, accessing international markets, or improving access to finance and to industry skills, were devolved to Creative Scotland, which was appointed to be leader of Scottish Creative Industries Partnership (Scottish Government, 2011).

Thanks to the information gained during the in-depth interview, the picture of the organizations involved in the system of supporting CI was captured. Figure 1 presents concrete organizations engaged in support services for creative businesses in Scotland. Quangos, like Scottish Enterprise or Skills Development Scotland, provide services dedicated to all sectors (generic level of support). Services tailored to the specific needs of creative industries are the main of Creative Scotland, Cultural Enterprise Office, and Interactive Scotland. The role of Scottish Funding Council should be perceived as a backup because its statutory duty is to invest in colleges and universities in Scotland, which indirectly supports CI. Organizations, such as trade unions and chambers of commerce, were not included in this group. Although they are a part of the business support landscape and belong to business support organizations, they are not directly connected with the public financing.

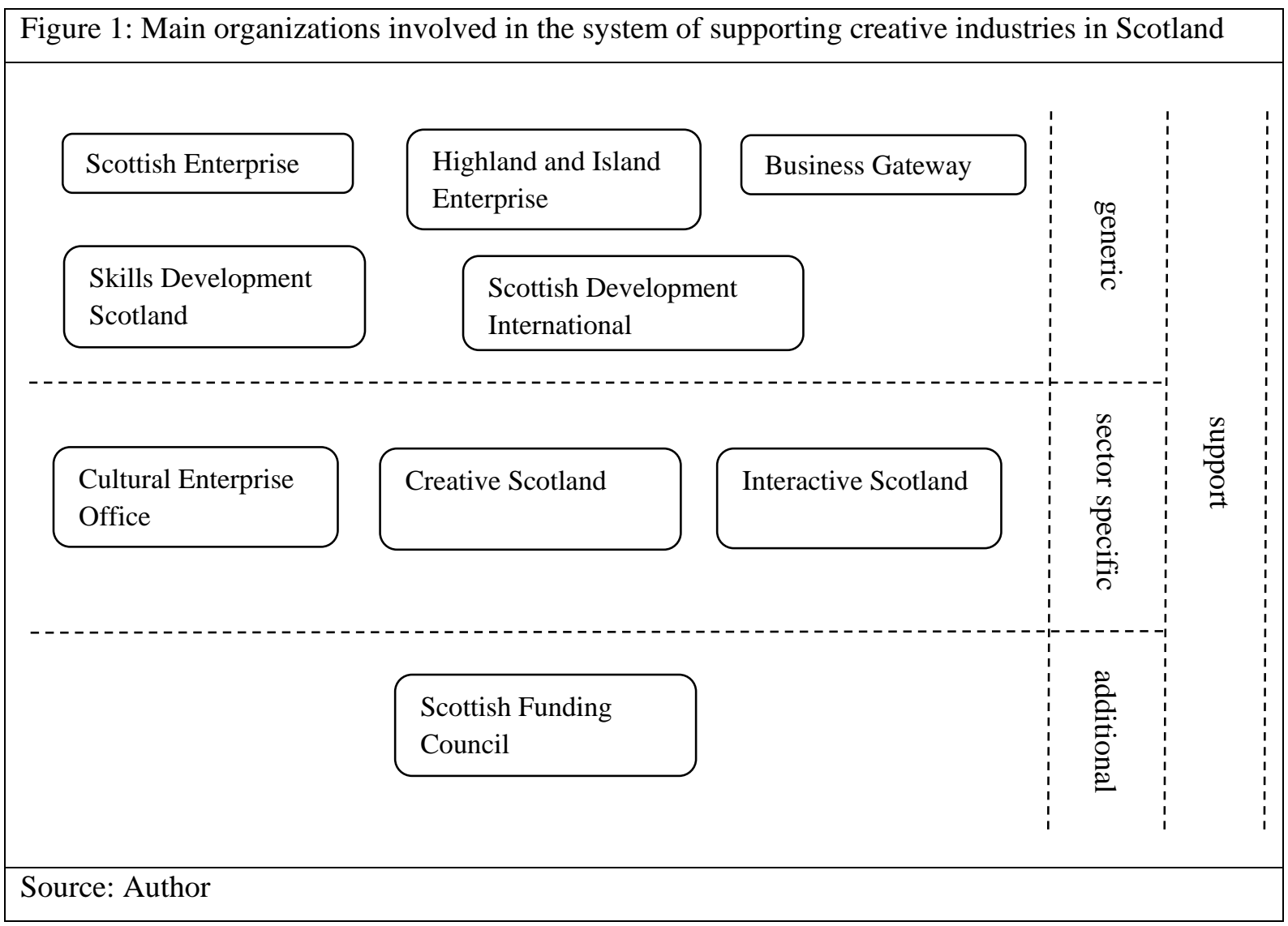

The question that arises in the first place is whether the above system provides services, which are helpful for various creative industries businesses. In the respondent's opinion, one of the biggest problems is generated by the DCMS classification, which encompasses too wide of a sectors range. Moreover, there is too little emphasis on digital media, which "destroys boundaries between CI sectors.” Therefore, from the respondent's point of view, DCMS is not a productive approach. Another 
problem that affects the support system is "a massive problem in assessing CI." This gives rise to a discussion concerning the starting point of the idea of supporting CI, which is the approach to their identification. This topic should be reviewed both by policy makers and academics.

The second issue, which emerged from the interview, was the specificity of CI in Scotland versus the trend of focusing on the gaming sector. "Games get a lot of headlines, but it is a small sector in Scotland. ... while designers are not properly recognized, not well understood.” As a result, designers are "largely ignored .... and under-supported sector." In this case, further discussion should be focused on raising the awareness of different sectors. It is probably easier by average people to notice creative work in games rather than, for example, in industrial machines.

The next problem, which was pointed out by the respondent, was the diversity of creative industries, which is a combination of two different worlds: business and art. This affects the way of measuring the effect of support directed toward arts and business. As the respondent said, some art societies objected strict economic rules constraining funding of artistic activity, as "there will no longer be support in art, but only investment." This is the issue connected with the effectiveness of public funding, which should perhaps pose different expectations toward artists and creative entrepreneurs.

Regardless of the opinion from some art society, the respondent emphasized that the funding system in Scotland works. But, the most important barrier in providing effective support system for creative industries in Scotland is the lack of policy. The document proposed by the Scottish Government (2011) states: “...is neither policy nor strategy.” "Nobody follows it and there is a mess.” The question that arise here are whether the Scottish Government engaged stakeholders from CI in the document development? And how is it executed?

\section{Conclusion}

The figures prove that creative industries have become more and more important part of today's economy, which has been especially observed in the UK. Scotland, known for its publishing, advertising, and music sectors, has undertaken some steps in order to build the system for supporting creative industries. According to the findings of the research, generic and sector specific support can be distinguished; nevertheless, this division seems to be insufficient as far as the great variety of CI is concerned. The interview showed that not only does art deserve a special attention, but some sectors also (e.g. design) need to be properly recognized as well.

In the prospect of the theoretical discourse, the research showed that classification of creative industries is still one of the key issues affecting the recognition and support for these sectors. Therefore, academics should pay more attention to re-drawing the boundaries of creative industries. Moreover, the interview indicated that a system for supporting CI needs to have clear and wellconstructed strategy. The policy-making process is crucial in terms of CI because without involving different stakeholders of creative industries, the execution of the strategy is difficult. Therefore, the article provides pillars for further discussion on the policy-making process, which would enable efficient realization of the policy shaping the creative environment.

\section{Acknowledgement}

The author is grateful for the financial support of the research provided by Dekaban-Liddle Foundation Glasgow Committee led by Dr. Aleksander Kovalenkov. The author also thanks Professor Colin Mason, Dr. Sabina Siebert, and Helen Mullen for valuable help in recognizing the specificity of creative industries in Scotland. 


\section{References}

Adorno, T., \& Horkheimer, M. (1979). The Dialectic of Enlightenment (J. Cumming, Trans.). London: Verso.

Bakhshi, H., Davies, J., Freeman, A., \& Higgs, P. (2015). The geography of the UK's creative and high-tech economies. Nesta. Retrieved from http://www.nesta.org.uk/

Cooke, P., \& Morgan, K. (1998). The Associational Economy: Firms, Regions and Innovation. Oxford: Oxford University Press.

DC Research Ltd., \& Cogentsi \& Pirnie Ltd., (2012, June). Economic Contribution Study: An Approach to the Economic Assessment of Arts \& Creative Industries in Scotland. Executive Summary. Retrieved from http://www.creativescotland.com/_data/assets/pdf_file/0011/21404/ECS-Executive-Summary-June-2012.pdf

Department for Culture, Media and Sport [DCMS] (1998). Creative Industries Mapping Document, British Government. Retrived from https://www.gov.uk/

Department for Culture, Media and Sport [DCMS] (2015, January). Creative Industries Economic Estimates January 2015, British Government Statistical Release. Retrived from https://www.gov.uk/

European Commission (2015). Supporting Europe's Culture and Creative Secotrs, Creative Europe Programme. Retrived from http://ec.europa.eu/culture/policy/cultural-creative-industries/index_en.htm

Florida R. (2002). The Rise of the Creative Class. And How It's Transforming Work, Leisure and Everyday Life. New York: Basic Books.

Howkins, J. (2001). The Creative Economy: How People Make Money From Ideas. New York: Penguin.

KEA European Affair [KEA] (2006). The economy of Culture in Europe. A study prepared for the European Commission (Directorate-Genaral for Education and Culture). Retrieved from http://ec.europa.eu/culture/library/studies/culturaleconomy_en.pdf

Kevin, M., (2004). Systems theory and the common-sense view of advisers. Journal of Small Business and Enterprise Development, 11(1), 114-120. doi: 10.1108/14626000410519146

Markiewicz, J. (2014). Koncepcja wspierania przemystów kreatywnych w ujęciu międzynarodowym i regionalnym [The concept of supporting creative industries in terms of international and regional]. Zeszyt Naukowy nr 796 Ekonomiczne Problemy Usług nr 110 [Scientific Notebook No. 796 Economic Problems of Services No. 110]. Wydawnictwo Naukowe Uniwersytetu Szczecińskiego, Szczecin, 30-40.

Miege, B., \& Garnham, N. (1979). The cultural commodity. Media, Culture \& Society, 1(3), $297-311$. doi: $10.1177 / 016344377900100307$

Mole, K., (2004). Systems theory and the common-sense view of advisers, Journal of Small Business and Enterprise Development, 11(1), 114-120. doi: 10.1108/14626000410519146

Penrose, E. T. (1995). The Theory of the Growth of the Firm (3rd ed.). Oxford: Basil Blackwell.

Pike, A., Rodriguez-Pose, A., \& Tomaney, J. (2006). Local and Regional Development. Abingdon, New York: Routledge.

Putnam, R. D., Leonardi, R., \& Nanetti, R.Y. (2001). Making Democracy Work. Princeton: Princeton University Press.

Regulation (EU) No. 1295/2013 (2013). Regulation (EU) No 1295/2013 of the European Parliament and of the Council of 11 December 2013 establishing the Creative Europe Programme 2014 to 2020 and repealing Decisions No 1718/2006/EC, No 1855/2006/EC and No 1041/2009/EC Text with EEA relevance. Retrieved from http://eur-lex.europa.eu/

Scottish Parliament (2008, March). Creative Scotland Bill (SP Bill 7). Edinburgh, Scotland: Scottish Parliamentary Corporate Body. Retrieved from http://www.scottish.parliament.uk

Scottish Government (2011). Growth, Talent, Ambition - the Government's Strategy for the Creative Industries. Edinburg. Crown ISBN 978178045155 8. Retrieved from http://www.gov.scot

TERA Consultants (2014). The Economic Contribution of the Creative Industries to EU GDP and Jobs. Retrived from http://www.teraconsultants.fr/en/issues/The-Economic-Contribution-of-the-Creative-Industries-to-EU-in-GDP-andEmployment 